\title{
Immunotherapy Updates in Advanced Hepatocellular Carcinoma
}

\author{
Amisha Singh ${ }^{1, \dagger}$, Ryan J. Beechinor ${ }^{2,+}{ }^{+}$, Jasmine C. Huynh ${ }^{3}\left(\mathbb{D}\right.$, Daneng Li $^{4}{ }^{(}$, Farshid Dayyani ${ }^{5}$, \\ Jennifer B. Valerin ${ }^{5}$, Andrew Hendifar ${ }^{6}$, Jun Gong ${ }^{6, \ddagger}$ and May Cho ${ }^{5, *, \neq}$
}

1 Internal Medicine, University of California, Davis, Sacramento, CA 95817, USA; drasingh@ucdavis.edu

2 UC Davis Comprehensive Cancer Center, Sacramento, CA 95817, USA; rbeechinor@ucdavis.edu

3 Hematology Oncology, University of California, Davis, Sacramento, CA 95817, USA; jachuynh@ucdavis.edu

4 Department of Medical Oncology, City of Hope Comprehensive Cancer Center and Beckman Research Institute, Duarte, CA 91010, USA; danli@coh.org

5 Hematology Oncology, University of California, Irvine, Irvine, CA 92868, USA; fdayyani@hs.uci.edu (F.D.); jvalerin@hs.uci.edu (J.B.V.)

6 Hematology Oncology, Cedars-Sinai Medical Center, Los Angeles, CA 90048, USA; andrew.hendifar@cshs.org (A.H.); jun.gong@cshs.org (J.G.)

* Correspondence: mayc5@hs.uci.edu

+ These authors contributed equally to this paper as first author.

$\ddagger$ These authors contributed equally to this paper as senior authors.

Citation: Singh, A.; Beechinor, R.J.; Huynh, J.C.; Li, D.; Dayyani, F.;

Valerin, J.B.; Hendifar, A.; Gong, J.;

Cho, M. Immunotherapy Updates in Advanced Hepatocellular Carcinoma. Cancers 2021, 13, 2164. https:// doi.org/10.3390/cancers13092164

Academic Editors: Alfred Sze-Lok Cheng and Lorenza Rimassa

Received: 16 April 2021

Accepted: 26 April 2021

Published: 30 April 2021

Publisher's Note: MDPI stays neutral with regard to jurisdictional claims in published maps and institutional affiliations.

Copyright: (c) 2021 by the authors. Licensee MDPI, Basel, Switzerland. This article is an open access article distributed under the terms and conditions of the Creative Commons Attribution (CC BY) license (https:// creativecommons.org/licenses/by/ $4.0 /)$.
Simple Summary: Advanced hepatocellular carcinoma (HCC) carries a grim prognosis, which has historically been compounded by a lack of available systemic therapies. Sorafenib monotherapy was the standard of care for front-line treatment of advanced HCC for many years, despite both poor tolerability and lack of durable responses. In the past few years, there have been several clinical trials evaluating the efficacy of immune checkpoint inhibitors for advanced HCC. Use of immune checkpoint inhibitors alone, and in combination with targeted therapies, has led to improved outcomes in both treatment-naïve and subsequent line treatment of advanced HCC. Here we review the role of immunotherapy in the treatment of HCC, describe the mechanistic basis for combination with targeted therapy, and summarize the recent published data as well as ongoing clinical trials for the use of immunotherapy in the treatment of advanced HCC.

Abstract: Hepatocellular carcinoma (HCC) is the second most common cause of cancer death worldwide. HCC tumor development and treatment resistance are impacted by changes in the microenvironment of the hepatic immune system. Immunotherapy has the potential to improve response rates by overcoming immune tolerance mechanisms and strengthening anti-tumor activity in the tumor microenvironment. In this review, we characterize the impact of immunotherapy on outcomes of advanced HCC, as well as the active clinical trials evaluating novel combination immunotherapy strategies. In particular, we discuss the efficacy of atezolizumab and bevacizumab as demonstrated in the IMbrave150 study, which created a new standard of care for the frontline treatment of advanced HCC. However, there are multiple ongoing trials that may present additional front-line treatment options depending on their efficacy/toxicity results. Furthermore, the preliminary data on the application of chimeric antigen receptor (CAR-T) cell therapy for treatment of HCC suggests this may be a promising option for the future of advanced HCC treatment.

Keywords: hepatocellular carcinoma; immunotherapy; immune checkpoint inhibitors; PD-1; PD-L1; CTLA-4; chimeric antigen receptor

\section{Introduction}

Hepatocellular carcinoma (HCC) represents $90 \%$ of all primary liver tumors and is estimated to be the second most common cause of cancer deaths worldwide [1]. Advanced HCC carries a particularly poor prognosis, as median overall survival (OS) without treatment is approximately eight months [2]. Over the past five years, increased understanding 
of the pathogenesis and heterogeneity of these tumors has led to substantial progress in the development of systemic therapies for the treatment of HCC. Specifically, the use of immune checkpoint inhibitors alone, as well as in combination with targeted therapies, has proven to be an effective strategy for patients with advanced HCC. This review will discuss the theoretical context of immunotherapies and evaluate their practical significance in treating advanced HCC.

\section{Role of Immunotherapy in HCC}

The liver is a unique anatomical organ in terms of its role in promoting immune tolerance. It is fed by a dual blood supply from both the hepatic artery and portal vein, which facilitates gut pathogen exposure to Kupffer cells (macrophages), natural killer cells, and innate $\mathrm{T}$ cells in the hepatic sinusoids [3]. The constant exposure to these foreign antigens requires immune tolerance mechanisms mediated by regulatory $\mathrm{T}$ cells (Treg) and immunosuppressive cytokines to limit excessive immune activity to harmless antigens [4]. The hepatic immune system facilitates an immunosuppressive environment, which can promote the growth and prevent the immune capture of malignant hepatocytes, thereby making hepatic tumors a potential target for immunotherapy.

The pathogenesis of HCC is rooted in known inflammatory risk factors such as toxins, non-alcoholic hepatic steatosis, and viruses such as hepatitis A and B. HCC often arises on a background of cirrhosis related to these insults, as maladaptive interactions between angiogenic cells, fibroblastic cells, and immune cells promote pathologic tumor growth [5]. Imbalances between immune-suppressive and immune-activating cells play an important role in the development of HCC, and these immunosuppressive changes in the tissue microenvironment may also have prognostic implications. In vitro assays have shown that increased Treg expression correlates with an increasing stage of HCC tumors [6]. Studies have also shown that increased Treg expression correlates with poor prognosis and propensity for metastatic disease [7-10]. Tregs diminish immune activity by impairing effector T cell (CD8+) infiltration and by reducing granzyme and perforin activity [6]. Tregs, in tandem with myeloid-derived suppressor cells (MDSC), also suppress antiviral immune responses by upregulating the expression of checkpoint inhibitors such as programmed cell death protein 1 (PD-1) and programmed cell death protein ligand-1 (PD-L1) [11-16]. PD-L1 upregulation subsequently diminishes cytokine production, promotes Treg differentiation, and blunts cytotoxic responses from effector $\mathrm{T}$ cells [17]. There is significant literature to support that PD-L1 expression is associated with higher tumor stage, increased tumor recurrence risk, and worse overall prognosis $[10,11,16,18]$. This is further supported by in vitro studies that show positive responses to PD-L1 blockade on reducing viral load, preventing tumor-derived immunosuppression, and slowing tumor progression [12].

Based on the pre-clinical data suggesting the potential role of immunotherapy in the treatment of HCC, a multitude of clinical trials have been performed evaluating its use in patients with advanced HCC. A summary of the pivotal trials of immunotherapy for the treatment of advanced hepatocellular carcinoma is shown in Table 1. Collectively, these data have transformed the treatment of HCC from the previous standard of single agent targeted oral therapy with either sorafenib or lenvatinib, to a new standard of care using immunotherapy combinations. Below we review key clinical trial data and highlight important ongoing research that will likely impact advanced HCC management in the future. 
Table 1. Published pivotal trials of immunotherapy for the treatment of advanced hepatocellular carcinoma.

\begin{tabular}{|c|c|c|c|c|c|}
\hline Trial Name & Phase & Setting & Target & Intervention & ${ }^{*}$ Key Results \\
\hline CHECKMATE-040 [19] & Phase I/II & $\begin{array}{l}\text { Previous progression or } \\
\text { intolerance to sorafenib }\end{array}$ & PD-1 inhibitor, CTLA-4 inhibitor & Nivolumab + ipilimumab (Arm A) & $\begin{array}{c}\text { ORR: } 32 \% \text {, CR: 5\% Median PFS: NA, } \\
\text { Median OS: } 22.8 \text { months }\end{array}$ \\
\hline CHECKMATE-459 [20] & Phase III & $\begin{array}{l}\text { First-line therapy for } \\
\text { treatment-naïve }\end{array}$ & PD-1 inhibitor & Nivolumab & $\begin{array}{l}\text { ORR: } 15 \% \text {, CR: } 4 \% \text {, Median PFS: } \\
3.6 \text { months, Median OS: } 16.4 \text { months }\end{array}$ \\
\hline KEYNOTE-224 [21] & Phase II & $\begin{array}{l}\text { Previous progression or } \\
\text { intolerance to sorafenib }\end{array}$ & PD-1 inhibitor & Pembrolizumab & $\begin{array}{l}\text { ORR: } 17 \% \text {, CR: } 1 \% \text {, Median PFS: } \\
4.9 \text { months, Median OS: } 12.9 \text { months }\end{array}$ \\
\hline KEYNOTE-240 [22] & Phase III & $\begin{array}{l}\text { Previous progression or } \\
\text { intolerance to sorafenib }\end{array}$ & PD-1 inhibitor & Pembrolizumab & $\begin{array}{l}\text { ORR: } 18.3 \% \text {, CR: } 2.2 \% \text {, Median PFS: } \\
3.0 \text { months, Median OS: } 13.9 \text { months }\end{array}$ \\
\hline IMbrave150 [23,24] & Phase III & $\begin{array}{l}\text { First-line therapy for } \\
\text { treatment-naïve, comparison } \\
\text { to sorafenib }\end{array}$ & VEGF inhibitor, PD-L1 inhibitor & Atezolizumab + bevacizumab & $\begin{array}{l}\text { ORR: } 27.3 \% \text {, CR: } 5.5 \% \text {, Median PFS: } \\
6.8 \text { months, Median OS: } 19.2 \text { months }\end{array}$ \\
\hline KEYNOTE-524 [25,26] & Phase Ib & $\begin{array}{l}\text { DLT then expansion group of } \\
\text { first-line therapy for } \\
\text { treatment-naïve }\end{array}$ & TKI, PD-1 & Lenvatinib + pembrolizumab & $\begin{array}{l}\text { ORR: } 46.0 \% \text {, CR: } 5.0 \% \text {, Median PFS: } \\
9.3 \text { months, Median OS: } 22 \text { months }\end{array}$ \\
\hline
\end{tabular}

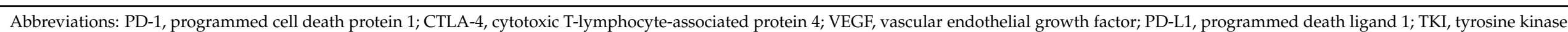
inhibitor; DLT, dose limiting toxicity; ORR, objective response rate; CR, complete response; PFS, progression free survival; OS, overall survival. * Results shown are those reported using RECIST 1.1. 


\section{Immune Checkpoint Inhibitor Monotherapy}

\subsection{Nivolumab}

Nivolumab is a fully humanized immunoglobulin G4 (IgG4) antibody against the PD-1 receptor. Through binding to PD-1, nivolumab prevents tumor cells from neutralizing $\mathrm{T}$ cell responses, thereby enhancing host $\mathrm{T}$ cell proliferation, increasing cytokine production, and leading to anti-tumor immune response [27]. The initial efficacy of nivolumab for the treatment of HCC was demonstrated in the CHECKMATE-040 trial, a multicenter, open-label phase I/II study of both sorafenib-naïve and sorafenib-treated patients with advanced HCC [19]. The trial was strict in its inclusion criteria, as only intermediate or advanced HCC patients with Child-Turcotte-Pugh class of A or better were included. Nivolumab was given intravenously (IV) every 2 weeks, and the study utilized a standard 3+3 design to determine the maximum tolerated dose ranging from $0.1-10 \mathrm{mg} / \mathrm{kg}$, with the dose-expansion phase proceeding with $3 \mathrm{mg} / \mathrm{kg}$ IV. The objective response rate (ORR) was 20\% (95\% CI: 15-26) in the dose-expansion phase, and 15\% (95\% CI: 6-28) in the dose-escalation phase [19]. Based on these results, in 2017, nivolumab was FDA approved for treatment of advanced HCC after sorafenib failure.

Subsequently in 2019, the CHECKMATE-459 trial compared nivolumab to sorafenib as a first line therapy for advanced HCC [20]. This phase III study enrolled 743 systemictherapy-naïve patients with advanced HCC, randomized to receive either nivolumab $240 \mathrm{mg}$ IV every 2 weeks or oral sorafenib $400 \mathrm{mg}$ by mouth twice a day. There was no statistically significant difference in the primary endpoint of median OS, which was 16.4 months with nivolumab versus 14.7 months with sorafenib (HR 0.85, 95\% CI: 0.72-1.02; $p=0.0752$ ). However, nivolumab demonstrated a better safety profile as adverse events $\geq$ grade 3 were reported in 81 patients (22\%) receiving nivolumab versus 179 patients (49\%) receiving sorafenib. In the nivolumab arm, patients with PD-L1 expression $\geq 1 \%$ demonstrated a higher ORR (28.2\% vs. $12.2 \%$ ) compared to those without, but this was not associated with PFS or OS benefit. However, comparing all enrolled patients with PD-L1 expression $\geq 1 \%$, median OS was greater in patients receiving nivolumab compared to sorafenib (16.1 months vs. 8.6 months) [20]. This supports the theoretical notion that PD-L1 status may influence outcomes with anti-PD1 therapies such as nivolumab. Based on data from CHECKMATE-459, nivolumab monotherapy is not considered to be superior to sorafenib in the front-line treatment of advanced HCC. Therefore, its primary utility as a first line agent is in patients who are ineligible or intolerant to tyrosine kinase inhibitors or anti-VEGF treatments.

\subsection{Pembrolizumab}

Pembrolizumab is a fully humanized IgG4 kappa monoclonal antibody against PD-1 with a similar mechanism of action as nivolumab [28]. Pembrolizumab was granted accelerated approval by the FDA for advanced HCC as second-line treatment after sorafenib based on the KEYNOTE-224 trial [21]. This open-label, single-arm phase II trial enrolled 104 patients with advanced HCC with intolerance or progression with sorafenib, ChildPugh A disease, and ECOG 0-1. Participants were treated with pembrolizumab $200 \mathrm{mg}$ IV every three weeks until toxicity or progression. The primary endpoint of ORR was 17\% (95\% CI: 11-26). Median OS was 12.9 months (95\% CI: 9.7-15.5), median PFS was 4.8 months (95\% CI: 3.4-7.2), and grade $\geq 3$ adverse effects were reported in $26 \%$ of patients [21].

Pembrolizumab was further evaluated for treatment of advanced HCC in the KEYNOTE240 trial. This was a phase III, randomized, double-blind trial comparing pembrolizumab $200 \mathrm{mg}$ IV every three weeks $(n=279)$ to placebo $(n=134)$ in 413 patients with advanced HCC previously treated with sorafenib [22]. As expected, patients receiving pembrolizumab demonstrated a higher ORR of $16.9 \%$ (95\% CI: 12.7-21.8\%) compared to placebo $2.2 \%$ (95\% CI: $0.5-6.4 \%)$. Surprisingly, the coprimary endpoint of OS and PFS failed to reach the prespecified one-sided level of statistical significance ( $p=0.0174$ and $p=0.002$, respectively) after a median follow-up of 13 months. The median OS was 13.9 months (95\% CI: 11.6-16.0) in the pembrolizumab arm versus 10.6 months (95\% CI: $8.3-13.5)$ in the placebo arm (HR 0.781; 95\% CI: 0.611-0.998; $p=0.0238)$. PFS was similar, 3 months (95\% CI: 
2.8-4.1) for pembrolizumab versus 2.8 months (95\% CI: 2,5-4.1) with placebo (HR: 0.775; 95\% CI: 0.609-0.987; $p=0.0186$ ). Treatment-related adverse events grade $\geq 3$ occurred in $18.6 \%$ of patients in the pembrolizumab arm and $7.5 \%$ of patients taking placebo, demonstrating similar tolerability as with KEYNOTE-224 [21,22]. Given that the design of this study was a non-active comparator arm, it is surprising that OS/PFS was not improved with pembrolizumab compared to placebo. However, it is important to note that prior to study enrollment, there were no FDA approved medications for the treatment of HCC after progression on sorafenib. During the conduct of the trial, both regorafenib and nivolumab were approved as second line agents in advanced HCC after sorafenib, and the use of either or both of these agents at progression may have impacted these results.

\subsection{Tremelimumab}

Tremelimumab is a fully humanized IgG2 monoclonal antibody against cytotoxic $\mathrm{T}$ lymphocyte-associated antigen (CTLA4) [29]. CTLA-4 is an extracellular receptor expressed on T cells and is a CD28 homolog. In this fashion, CTLA-4 binds to B7 ligands expressed on antigen presenting cells (APC), and does so with a higher affinity than CD28. However, unlike CD28, which produces a costimulatory effect on T cells, CTLA-4 leads to T cell anergy, as it prevents the $\mathrm{CD} 28 / \mathrm{B} 7$ costimulation required for $\mathrm{T}$ cell activation and proliferation. Therefore, CTLA- 4 inhibitors facilitate immune-mediated anti-tumor response by antagonizing CTLA-4/B7 interactions, enabling CD28/B7 costimulatory interactions, and subsequently leading to direct activation and expansion of effector $\mathrm{T}$ cells which can target cancer antigens [28-30].

Tremelimumab was initially evaluated for use in advanced HCC in a 21-patient cohort of HCV-associated advanced HCC [31]. Patients were permitted to have previous treatment after a washout of at least 4 weeks, and 5/21 (23.8\%) had previously received sorafenib. Patients were treated with tremelimumab at a dose of $15 \mathrm{mg} / \mathrm{kg}$ IV every 90 days until tumor progression or medication intolerance. The study noted a median time to progression of 6.5 months (95\% CI: 3.95-9.14) with a median OS of 8.2 months (95\% CI: 4.6-21.4). Importantly, tremelimumab demonstrated an acceptable toxicity profile in these patients with impaired liver function as well as a potential antiviral effect against HCV, and thus results help support future studies of CTLA-4 inhibitors in advanced HCC [31]. A recent phase II study (Study 22) that contained a tremelimumab monotherapy arm was presented at the 2020 American Society of Clinical Oncology (ASCO, Alexandria, VA, USA) Annual Meeting, and details of this trial are discussed later [32,33]. Additionally, the activity of tremelimumab when combined with radiofrequency thermal ablation (RFA) or transarterial chemoembolization (TACE) has also been evaluated for patients with advanced HCC [34]. Patients in this study were heavily pre-treated, as $21 / 28(75 \%)$ had previously received sorafenib. Tremelimumab was given at two doses $(3.5 \mathrm{or} 19 \mathrm{mg} / \mathrm{kg}$ ) IV every 4 weeks for 6 doses, then every 90 days until off treatment. Authors reported a median time to progression of 7.4 months (95\% CI: 4.7-19.4) and median OS of 12.3 months (95\% CI: 9.3-15.4) [34]. Based on this data, the combination of immunotherapy with direct disease interventions such as TACE or RFA represents a promising strategy for HCC, as these procedures expose tumor antigens, which may prime APCs for a more robust immune-mediated $\mathrm{T}$ cell response.

\subsection{Durvalumab}

Durvalumab is a humanized immunoglobulin G1k monoclonal antibody against the PD-L1 ligand [35]. Its mechanism is similar to that of pembrolizumab and nivolumab; however, durvalumab binds to the PD-L1 ligand, which is upregulated on cancer cells, rather than the PD-1 receptor on activated T cells. Inhibition of the PD-L1 ligand prevents it from downregulating T cells through its interaction with the PD-1 receptor, and thus leads to immune-mediated tumor cell recognition and killing [28,35]. The efficacy of durvalumab as monotherapy for patients with several tumor types, including advanced HCC, was investigated in a phase I/II, multicenter, open label study [36]. Patients enrolled (36/40) 
were heavily pre-treated with sorafenib. Patients were administered durvalumab $10 \mathrm{mg} / \mathrm{kg}$ IV every 2 weeks for 12 months or until complete response. Preliminary results, available in an abstract, demonstrated a median OS of 13.2 months (95\% CI: 6.3-21.1) and a response rate of $4 / 39(10.3 \%)$. Durvalumab was well-tolerated, as no patients discontinued therapy due to treatment associated adverse effects. This data demonstrated the potential efficacy of durvalumab in the treatment of advanced HCC and led to its ongoing study in combination with other immunotherapy discussed later.

\section{Combination Strategies with Immune Checkpoint Inhibitors}

\subsection{Atezolizumab and Bevacizumab}

Among the ongoing clinical trials for advanced HCC, the combination of vascular endothelial growth factor (VEGF) inhibitors with immune checkpoint inhibitors may hold the greatest promise. HCC tumors' carcinomas are heavily vascularized with rich arterial flows, driven in part by increased VEGF expression and angiogenesis [37]. In addition to its angiogenic effects, VEGF increases the recruitment of regulatory T cells, increases MDSC, and decreases the infiltration of effector T cells in tumors by inducing Fas ligand expression on tumor endothelium [38,39]. This effectively creates an inactive and walled off tumor microenvironment, and thus may limit the efficacy of immunotherapy alone. Furthermore, immune checkpoint inhibitors have been shown to promote normalization of vasculature. [40] Therefore, combination strategies targeting both VEGF and immune checkpoint molecules may be necessary to prevent MDSC- and Treg-mediated immunosuppression, strengthen effector $\mathrm{T}$ cell response, and ensure antiangiogenic effects in order to achieve optimal treatment outcomes [41].

Atezolizumab is a humanized IgG1 kappa immunoglobulin monoclonal antibody against PD-L1, and has an identical mechanism of action as durvalumab, described previously [28,42]. Atezolizumab was originally FDA approved in 2016 for metastatic non-small cell lung carcinoma, and it has subsequently been shown to be effective against many tumor types, including advanced urothelial carcinomas, triple negative breast cancer, metastatic melanoma, and HCC [43].

Bevacizumab is a humanized monoclonal IgG1 antibody that blocks VEGF and its downstream angiogenic and immunosuppressive effects. This blockade allows dendritic cell maturation and reduced regulatory T cell activity in the tumor microenvironment [44]. Bevacizumab has been used in combination with cytotoxic chemotherapy for a variety of solid malignancies and has only recently been investigated in combination with immunotherapy [45]. As both atezolizumab and bevacizumab target immunosuppressive regulatory T cell activity through different mechanisms, the combination of atezolizumab and bevacizumab is theorized to synergistically increase cytotoxic $T$ cell attacks against tumor cells [41].

The combination of atezolizumab and bevacizumab was first investigated for the treatment of advanced HCC in a randomized phase Ib study (GO30140) comparing atezolizumab monotherapy to atezolizumab plus bevacizumab in 119 treatment-naïve patients $[46,47]$. The study enrolled 223 patients who were randomized either to atezolizumab $1200 \mathrm{mg}$ IV every 3 weeks, with or without the addition of bevacizumab $15 \mathrm{mg} / \mathrm{kg}$ IV every 3 weeks (Arm F), or to a single-arm study of the combination of atezolizumab plus bevacizumab with the same dosing (Arm A). In Arm F, the median PFS was 5.6 months (95\% CI: 3.6-7.4) in the patients treated with atezolizumab plus bevacizumab, compared to 3.4 months (95\% CI: 1.9-5.2) in the atezolizumab monotherapy arm, which was statistically significant (HR 0.55, $p=0.0108$ ). Grade $\geq 3$ adverse effects were greater in the combination arm $(20 \%)$ compared to atezolizumab monotherapy (5\%). In Arm A, patients treated with atezolizumab plus bevacizumab had an ORR of 37/104 (36\%). Adverse effects were notably higher in this single arm, as $39 \%$ of subjects had grade $\geq 3$ adverse effects. These data suggested that this combination was a potential front-line treatment option for advanced HCC $[46,47]$. Subsequent evaluation of this combination was performed in the IMbrave150 trial, which was a Phase III open-label trial that enrolled 501 systemic-therapy-naïve pa- 
tients $[23,24]$. Notably, unlike the KEYNOTE-240 trial, this trial allowed the inclusion of patients with main portal vein invasion. Patients were randomized to receive either atezolizumab $1200 \mathrm{mg}$ IV plus bevacizumab $15 \mathrm{mg} / \mathrm{kg}$ IV every 3 weeks $(n=336)$ or sorafenib $400 \mathrm{mg}$ twice a day $(n=165)$ until progression or intolerable toxicity. After a median follow-up period of 15.6 months, median OS was 19.2 months with combination therapy versus 13.4 months with sorafenib (HR, 0.66, 95\% CI: $0.52-0.85, p=0.0009$ ). At 18 months, the survival rate was $52 \%$ in the combination cohort versus $40 \%$ with sorafenib. ORR was also higher with atezolizumab plus bevacizumab than with sorafenib (29.8\% vs. $11.3 \%)$. The side effect profile was comparable between these regimens [23,24].

The results of the IMbrave150 trial set a new standard of care for the first-line treatment of advanced HCC, and there are several important implications of this trial that merit further discussion. First, atezolizumab plus bevacizumab is now the only therapy to demonstrate improved OS and PFS for the first-line treatment of advanced HCC compared to sorafenib. Importantly, the median OS of 13.4 months seen in the sorafenib arm of the IMbrave150 study is numerically greater than previous reports of front-line sorafenib use in both the SHARP study (10.7 months) and REFLECT study (12.3 months). This increase in OS occurred despite similar PFS seen in the sorafenib arms of the IMbrave150 study (4.3 months) when compared to that of the sorafenib arms in SHARP (5.5 months) and REFLECT (3.7 months) [2,23,48]. Therefore, the improved OS in the sorafenib arm of the IMbrave150 study occurred with a similar duration of sorafenib treatment, and this benefit likely represents the additional availability of second-line immunotherapy and TKIs in advanced HCC. Although the median OS with atezolizumab and bevacizumab was not reached in the original IMbrave150 publication, long term follow-up demonstrated this combination led to a 3.6-month advancement in median OS compared to sorafenib [24]. Secondly, this combination was well-tolerated, as the majority of adverse events were either infusion reactions or hypertension, and grade $\geq 3$ bleeding rates as well as immunemediated adverse events were rare $(<10 \%)$. One reason for the low rate of bleeding may be that patients were excluded if they had untreated varices at baseline, and it will therefore be important in clinical practice to perform baseline upper endoscopies to mitigate this risk, as this was a requirement of the trial protocol $[23,24]$. To this point, it is also important to highlight the contraindications to this regimen. which include patients with autoimmune diseases, those with coinfection with hepatitis B or C, or those at high risk of bleeding. A third consideration is that only $15 \%$ of patients in IMbrave150 had Barcelona clinic liver stage B disease, and TACE is traditionally a consideration in this patient population. These patients have the potential for tumor downstaging to enable them to be candidates for surgery and/or transplantation, and thus their candidacy for this combination immunotherapy must be considered on a case-by-case basis. Lastly, the use of this immunotherapy combination up front will complicate the HCC treatment algorithm, as there is currently no available data to guide the treatment for patients who progress on this combination. For this reason, it is critically important that these patients be prioritized for clinical trials, as it is unknown whether therapies such as sorafenib or lenvatinib have efficacy after progression on an immunotherapy combination.

\subsection{Tremelimumab and Durvalumab}

The combination of CTLA-4 and PD-L1 inhibitors is believed to have the synergistic ability to overcome immune checkpoint resistance and induce anti-tumor activity [49]. A phase II multi-arm trial (Study 22) of durvalumab plus tremelimumab in 433 advanced HCC patients with intolerance or progression on sorafenib has shown promising results $[32,33]$. Patients in this study were treated with one of four possible regimens: Arm 1-tremelimumab $300 \mathrm{mg}$ IV $\times 1$ plus durvalumab $1500 \mathrm{mg}$ IV every 4 weeks; Arm 2-durvalumab 1500 mg IV every 4 weeks; Arm 3-tremelimumab 750 mg IV every 4 weeks $\times 7$ doses then every 12 weeks thereafter; or Arm 4 -tremelimumab $75 \mathrm{mg}$ IV $\times 4$ plus durvalumab 1500 mg IV every 4 weeks. Reported median OS between the arms was as follows: 18.7 months, 13.6 months, 15.1 months, and 11.3 months for arms $1-4$, re- 
spectively. Additionally, the reported ORR were $24.0 \%, 10.6 \%, 7.2 \%$, and $9.5 \%$, respectively. Toxicity data for these combinations is incomplete, but serious adverse events including death ranged from $10.9 \%$ up to $24.9 \%$ among the four arms [32,33]. Driven by the success of the phase II study, the ongoing phase III HIMALAYA trial (NCT03298451) with durvalumab and tremelimumab will test this combination as a first-line treatment for advanced HCC [50]. HIMALAYA is the first phase III study evaluating combined immune checkpoint inhibition in the first line treatment of advanced HCC. Patients will be randomized to one of three treatment arms: durvalumab monotherapy, durvalumab and tremelimumab combination therapy, or standard of care sorafenib. It is being conducted in over 186 centers across 16 countries, and the primary end point is OS [50]. If results demonstrate improved outcomes compared to sorafenib, it could provide another front-line treatment for advanced HCC and notably provide an alternative without antiangiogenic effects.

\subsection{Nivolumab and Ipilimumab}

Another dual immune checkpoint inhibitor combination, that of nivolumab and ipilimumab, was recently granted FDA approval for second-line therapy in sorafenibrefractory advanced HCC. Ipilimumab is a CTLA- 4 monoclonal antibody with an identical mechanism of action as tremelimumab [18]. The combination of nivolumab and ipilimumab was studied in an expansion arm of the CHECKMATE-040 phase I/II trial, which compared outcomes among three dose combinations: Arm A was treated with nivolumab $1 \mathrm{mg} / \mathrm{kg}$ IV and ipilimumab $3 \mathrm{mg} / \mathrm{kg}$ IV every 3 weeks $(n=50)$; Arm B with nivolumab $3 \mathrm{mg} / \mathrm{kg}$ IV and ipilimumab $1 \mathrm{mg} / \mathrm{kg}$ IV every 3 weeks followed by nivolumab $240 \mathrm{mg}$ IV every 2 weeks $(n=49)$; and Arm C with nivolumab $3 \mathrm{mg} / \mathrm{kg}$ IV every 2 weeks and ipilimumab $1 \mathrm{mg} / \mathrm{kg}$ IV every 6 weeks $(n=49)$ [51]. Therapy was generally well tolerated, and serious adverse events were rare. Arm A showed the most impressive outcomes with a 12-month OS rate of $61 \%$ (95\% CI: 46-73\%) and a 24-month OS rate of $48 \%$ (95\% CI: $34-61 \%$ ). Long-term results from a minimum 44-month follow-up period for Arm A showed an impressive median OS of up to 22 months and ORR of $32 \%$. The objective response rates were similar across subgroups including hepatitis infection status, presence of vascular invasion and/or extrahepatic spread, and prior sorafenib treatment [51]. Interestingly, PD-L1 expression $\geq 1 \%$ was associated with an increased median OS (28.1 months vs. 16.6 months), whereas inflammatory biomarkers were not associated with differences in OS [52]. Similar to other combinations, results in this sorafenib-treated population have led to development of trials evaluating this combination in treatment-naïve patients. The open label phase III CHECKMATE 9DW trial comparing nivolumab plus ipilimumab versus sorafenib or lenvatinib as first-line treatment for advanced HCC is currently enrolling [53]. Depending on the results of the CHECKMATE 9DW and HIMALAYA trials, dual immune checkpoint inhibitor combinations could become another front-line treatment option for advanced HCC.

\subsection{Tyrosine Kinase Inhibitor and PD-L1 Inhibitors}

Lenvatinib is a small molecule tyrosine kinase inhibitor that opposes tumor angiogenesis by inhibiting VEGFR1-3, fibroblast growth factor receptor (FGFR1-4), and plateletderived growth factor receptor $\alpha$ (PDGFR $\alpha$ ) [54]. In 2018, Lenvatinib was granted FDA approval for first-line treatment of advanced HCC based on its efficacy demonstrated in the phase III REFLECT trial, where it was found to be non-inferior to sorafenib [48]. Given its multiple targets and efficacy as monotherapy, lenvatinib is currently being investigated in combination with immunotherapy for the front-line treatment of advanced HCC. The KEYNOTE-524 trial was an open-label, single arm, phase Ib study which evaluated the addition of pembrolizumab to lenvatinib in treatment-naïve patients with unresectable HCC $[25,26]$. The first 6 patients were evaluated in a dose-limited toxicity phase, and the remaining 100 patients were treated with an expansion phase of lenvatinib $8 \mathrm{mg}$ (if $<60 \mathrm{~kg}$ ) or $12 \mathrm{mg}$ (if $>60 \mathrm{~kg}$ ) by mouth daily plus pembrolizumab $200 \mathrm{mg}$ IV every 3 weeks. Results show a median OS of 22 months (95\% CI: 20.4-NE), median PFS of 8.6 months 
(95\% CI: 7.1-9.7), and ORR of 36\% (95\% CI: 26.6-46.2). This combination is associated with a high degree of toxicity, as grade 3 adverse effects were reported in 67/100 (67\%) of patients, including 3 deaths related to study treatment (all respiratory failure) $[25,26]$. Spurred by these results, the LEAP-002 trial is a multicenter phase III study that plans to enroll 750 patients assigned to receive either lenvatinib 8 or $12 \mathrm{mg}$ by mouth daily with pembrolizumab $200 \mathrm{mg}$ IV every 3 weeks or lenvatinib plus placebo. The study will look at primary outcomes of PFS and OS and seek support for the regulatory approval of this combination $[55,56]$.

With their success in hematological malignancies, chimeric antigen receptor-modified $\mathrm{T}(\mathrm{CAR}-\mathrm{T})$ cell therapies are now being employed against solid malignancies including HCC $[57,58]$. CAR-T cells are composed of an antigen recognition domain that guides cell affinity and immunogenicity, a hinge-spacer region that allows flexibility, a transmembrane domain that assists in cytokine release, and an intracellular domain that enables $\mathrm{T}$ cell activation and subsequent cytokine release. Newer generation CAR-T cells also consist of costimulatory molecules to enhance activation and cytokine release [59,60].

Glypican-3 (GPC-3) has been a popular tumor associated antigen (TAA) for CAR-T therapy in HCC [61]. Although GPC-3 expression is historically associated with a worse prognosis in HCC, its overexpression on tumor cells can be leveraged to increase the effectiveness of CAR-T therapy. Anti-GPC-3 CAR-T cells have demonstrated powerful cytotoxic responses in HCC cell lines and in vivo experiments. Clinical trials using antiGPC-3 CAR-T cells are currently ongoing [61-63].

Alpha-fetoprotein (AFP) is another glycoprotein that is overexpressed by HCC tumor cells and is well-known as a tumor biomarker in HCC. Unlike GPC-3, which is a cell surface protein, AFP is processed intracellularly and presented on the cell surface by Class I MHC complexes [64]. To overcome this barrier, Liu et al. generated AFP CAR-T cells that specifically bind the AFP158-166 peptide complexed with human leukocyte antigen (HLA)-A*02:01. In vivo studies with xenograft models of human HLA-A*02:01+/AFP+ tumors showed significant regression with AFP CAR-T cells [65]. Currently, there are trials being developed to optimize the AFP T cell construct for treatment of advanced HCC [66].

Potential barriers to CAR-T efficacy in HCC include tumor neovascularization and tumor epithelialization, which may prevent adequate CAR-T cell infiltration. Resistance may also develop from proliferation of tumor cells that do not express the CAR-T target antigens. However, fourth generation CAR-T cells are being designed to enhance IL-12 production. This would significantly boost the immunogenicity and ability of CAR-T cells to target nearby antigen-negative cells $[67,68]$. Another strategy to overcome resistance is to create bispecific antibodies that can neutralize two antigens at a time or bring together a duo of T cells to enhance their immunogenicity. A phase I trial for ERY974, an anti-glypican 3/CD3 bispecific antibody, is currently recruiting for solid tumors including HCC [69]. Furthermore, as described above, the introduction of AFP CAR-T cells has paved the way for generating CAR-T cells that target intracellular antigens in solid tumors.

\section{Management of Immune Related Adverse Events (irAEs)}

Immune-related adverse events (irAEs) can affect a multitude of organ systems, have a unique delay in onset of toxicity, and present a particular challenge in patients with HCC due to the incidence of viral hepatitis and liver cirrhosis in this patient population [70,71]. While irAEs are generally reversible and dose-dependent, irAEs can be life threatening if not properly managed, as larger meta-analyses have reported the incidence of fatal irAEs to be approximately $0.64 \%$ (42 fatal irAEs in 6528 patients) [72] A comprehensive discussion of the management of irAEs is beyond the scope of our review, as there are several recent guidelines addressing this topic [73-75]. The incidence of irAEs in patients with HCC is no different than that of other cancer patients treated with immunotherapy, and therefore these guidelines are highly relevant [70].

However, it is worth mentioning the toxicity profile of the combination of bevacizumab with atezolizumab from the IMbrave150 trial, given its potential role as the new 
standard of care. Common adverse effects of Grade 3 or more with atezolizumab and bevacizumab included hypertension (15.2\%), aspartate aminotransferase increase (7\%), alanine transferase increase (3.6\%), proteinuria (3\%), and platelet count decrease (3.3\%). Notably, patients receiving atezolizumab and bevacizumab experienced slightly fewer Grade 5 events compared to the sorafenib group (4.6\% vs. 5.8\%). Grade 5 events, though rare, included esophageal or other gastrointestinal hemorrhage, possibly attributable to the anti-VEGF effects of this combination [23]. Despite these adverse effects, compared to the sorafenib arm, patients treated with atezolizumab and bevacizumab had a shorter median duration of therapy (7.4 months vs. 8 months), achieved a higher median dose intensity of immunotherapy (95\% vs. $85 \%$ ), and a lower incidence of treatment related deaths (4.6\% vs. 5.8\%) [23].

Although there are detailed guidelines for the management of these toxicities, in general, bevacizumab should be discontinued for thromboembolic events, gastrointestinal perforation, or Grade 3 or higher hemorrhagic events. Furthermore, bevacizumab doses should be skipped rather than dose-reduced if patients experience adverse reactions. Atezolizumab should be discontinued for Grade 3 or higher pneumonitis or hepatitis. Additionally, it should be discontinued for any recurrent Grade 3 adverse effects. For atezolizumab-related colitis, there is a role for corticosteroids with Grade 2 or 3 toxicities, though treatment should be discontinued for Grade 4 colitis [73-75].

\section{Future Directions}

There are several key ongoing trials for the use of immunotherapy in HCC shown in Table 2. These include optimizing the use of biomarkers to identify responders to immunotherapy, overcoming resistance, and the potential role of immunotherapy in adjuvant HCC, each of which are detailed below.

Table 2. Ongoing pivotal trials of immunotherapy for the treatment advanced hepatocellular carcinoma.

\begin{tabular}{|c|c|c|c|c|c|}
\hline Trial Name & Phase & Setting & Target & Intervention & Study Details \\
\hline $\begin{array}{c}\text { CHECKMATE- } \\
\text { 9DW } \\
\text { [53] }\end{array}$ & Phase III & $\begin{array}{l}\text { First-line therapy for } \\
\text { treatment-naïve, } \\
\text { comparison to } \\
\text { sorafenib or lenvatinib }\end{array}$ & $\begin{array}{l}\text { PD-1 inhibitor, } \\
\text { CTLA-4 inhibitor }\end{array}$ & $\begin{array}{l}\text { Nivolumab + } \\
\text { ipilimumab }\end{array}$ & $\begin{array}{c}\text { Enrollment: } 650 \\
\text { participants Estimated } \\
\text { Completion: } \\
\text { September } 2023\end{array}$ \\
\hline NCT03764293 [76] & Phase III & $\begin{array}{l}\text { First-line therapy for } \\
\text { treatment-naïve, } \\
\text { comparison to } \\
\text { sorafenib }\end{array}$ & TKI, PD-1 inhibitor & $\begin{array}{c}\text { Camrelizumab } \\
(\text { SHR-1210) }+ \\
\text { apatinib }\end{array}$ & $\begin{array}{c}\text { Estimated Enrollment: } \\
510 \text { participants } \\
\text { Estimated Completion: } \\
\text { June } 2022\end{array}$ \\
\hline COSMIC-312 [77] & Phase III & $\begin{array}{l}\text { First-line therapy for } \\
\text { treatment-naiive, } \\
\text { comparison to } \\
\text { sorafenib }\end{array}$ & $\begin{array}{l}\text { TKI, PD-L1 } \\
\text { inhibitor }\end{array}$ & $\begin{array}{l}\text { Atezolizumab }+ \\
\text { cabozantinib }\end{array}$ & $\begin{array}{l}\text { Estimated Enrollment: } \\
740 \text { participants } \\
\text { Estimated Completion: } \\
\text { December } 2021\end{array}$ \\
\hline $\begin{array}{l}\text { HIMALAYA } \\
{[50,78]}\end{array}$ & Phase III & $\begin{array}{l}\text { First-line therapy for } \\
\text { treatment-naive, } \\
\text { comparison to } \\
\text { sorafenib }\end{array}$ & $\begin{array}{l}\text { PD-1 inhibitor, } \\
\text { CTLA-4 inhibitor }\end{array}$ & $\begin{array}{l}\text { Durvalumab + } \\
\text { tremelimumab }\end{array}$ & $\begin{array}{c}\text { Estimated Enrollment: } \\
1504 \text { participants } \\
\text { Estimated Completion: } \\
\text { April } 2022\end{array}$ \\
\hline LEAP-002 [56] & Phase III & $\begin{array}{l}\text { First-line therapy for } \\
\text { treatment-naiive, } \\
\text { comparison to } \\
\text { lenvatinib }\end{array}$ & TKI, PD-1 inhibitor & $\begin{array}{c}\text { Lenvatinib }+ \\
\text { pembrolizumab }\end{array}$ & $\begin{array}{c}\text { Estimated Enrollment: } \\
750 \text { Estimated } \\
\text { Completion: May } 2022\end{array}$ \\
\hline ORIENT-32 [79] & Phase II/III & $\begin{array}{l}\text { First-line therapy for } \\
\text { treatment-naive, } \\
\text { comparison to } \\
\text { sorafenib }\end{array}$ & $\begin{array}{l}\text { PD-1 inhibitor, } \\
\text { VEGF }\end{array}$ & Sintilimab + IBI308 & $\begin{array}{c}\text { Estimated Enrollment: } \\
595 \text { Estimated } \\
\text { Completion: } \\
\text { December } 2022\end{array}$ \\
\hline $\begin{array}{l}\text { RATIONALE-301 } \\
\text { [80] }\end{array}$ & Phase III & $\begin{array}{l}\text { First-line therapy for } \\
\text { treatment-naiive, } \\
\text { comparison to } \\
\text { sorafenib }\end{array}$ & PD-1 inhibitor & Tislelizumab & $\begin{array}{c}\text { Estimated Enrollment: } \\
\text { 674 Estimated } \\
\text { Completion: May } 2022\end{array}$ \\
\hline
\end{tabular}

Abbreviations: PD-1, programmed cell death protein 1; CTLA-4, cytotoxic T-lymphocyte-associated protein 4; TKI, tyrosine kinase inhibitor; PD-L1, programmed death ligand 1; CAR-T, chimeric antigen receptor-modified T cell. 


\subsection{Emerging Biomarkers for Monitoring Response to Immunotherapies in HCC}

With an influx of clinical trials studying novel checkpoint inhibitor combinations, PD-L1 expression is being increasingly studied as a biomarker for monitoring response to immunotherapy. Although previous studies have correlated PD-L1 expression with poor prognosis in advanced HCC, data from CHECKMATE-040 and KEYNOTE-224 trials do not demonstrate any strong correlation between PD-L1 expression and ORR [21,51]. However, there is significant inter-institutional variability in the methods used to determine PD-L1 expression, which could confound data from multicenter clinical trials. Ideally, participating institutions should also set uniform sensitivity cutoffs for determining positive PD-L1 status. Furthermore, as PD-L1 expression is dynamic with disease progression, it would be important to sub-classify advanced HCC patients to allow comparison between patients with similar tumor burdens. To this point, there is currently no data delineating the optimum timing for performing immunohistochemical analysis on HCC tissue samples to determine PD-L1 expression. Additionally, the source of PD-L1 expression (stromal vs. tumoral vs. combined) is yet to be standardized. Overall, the variability in the immunohistochemical analyses of PD-L1 expression limits its practical utility for assessing response to immunotherapy [81].

As the landscape of HCC tumors is constantly shaped by competing immune-suppressive and immune-activating players, it is reasonable to monitor tumor-infiltrating lymphocyte density to gauge the expected responses to treatment. Indeed, high intratumoral densities of CD3+ and CD8+ T cells have been associated with a longer recurrence-free survival. A study by Kaseb et al. showed that, in patients treated with nivolumab and ipilimumab, clinical responses correlated with CD8+ infiltration [82]. However, as T cell infiltration is expected to increase with chronic viral infection, the presence of chronic hepatitis $C$ infection could confound these results. More research is needed to determine whether this class of patients would derive greater benefit from checkpoint inhibitors.

Another way to measure a tumor's immunogenic potential is to measure its tumor mutational burden. Tumor mutational burden (TMB) represents the number of somatic mutations present in a tumor genome, with a high TMB defined as $\geq 10$ mutations per mega-base (mut/mb) $[83,84]$. While TMB is emerging in popularity as a biomarker in various cancers, the relatively low TMB in HCC (median TMB of $5 \mathrm{mut} / \mathrm{mb}$ ) has impeded its applicability. A comprehensive genomic profiling study of 755 advanced HCC patients by Ang et al. found the median TMB for the entire cohort to be on the lower end with $4 \mathrm{mut} / \mathrm{mb}$. The authors also found no significant correlation between TMB and responders, progressors, or stable disease; this underscores the limited value of TMB as a current biomarker in HCC [85].

As HCC tumors are heterogeneous with distinct tumor microenvironment phenotypes, it is perhaps beneficial to classify tumors into grouped genetic profiles as opposed to individual biomarker classes. For instance, Thorsson et al. conducted an immunogenomic analysis and classified tumors into six different phenotypes. Four genetic "clusters" were identified as most common: lymphocyte depleted, inflammatory, wound healing, and interferon- $\gamma$ dominant. In this manner, understanding the clustering of genes that helps create specific immune escape mechanisms could help guide the most synergistic combination therapies [86]. Creating grouped genetic profiles could also allow researchers to identify subgroups of patients who could benefit from targeted combination therapies.

\subsection{Overcoming Resistance to Immunotherapy}

Novel combination regimens of immunotherapy with targeted therapy carry the promise of decreasing the rate of immune checkpoint inhibitor resistance. In addition to the published results at the time of this review, there are a multitude of ongoing clinical trials that will add to this literature in the near future (Table 2). Furthermore, it is possible that optimization of these combinations may enhance response rates in patients who have progressed on standard immune checkpoint inhibitor regimens. Several VEGF plus TKI plus immune checkpoint inhibitor combinations have shown efficacy in those previously treated with immune checkpoint inhibitors in other tumor types such as renal 
cell carcinoma, and these could be potentially adapted to HCC [87]. An example of this is the combination of lenvatinib plus pembrolizumab, which is being evaluated in metastatic renal cell carcinoma patients who progressed on immune checkpoint inhibitor treatment [88].

There are a variety of other immune targets that hold promise for future drug development in HCC and may help mitigate resistance to immune checkpoint inhibition. One example is transforming growth factor (TGF- $\beta$ ), which plays a role in modulating regulatory CD4+ T cell interaction with malignant hepatocytes. Pre-clinical data has shown that TGF- $\beta 1$ inhibition can overcome primary resistance to immune checkpoint blockade in an animal model without toxicity concerns noted for pan TGF- $\beta$ inhibitors [89]. A second is the lymphocyte activation gene-3 (LAG-3), which has multiple effects on T cell function and has been shown to be upregulated in CD8+ lymphocytes in patients with HCC [90]. Additionally, T cell immunoglobulin and mucin domain containing-3 (TIM-3) is a protein expressed on CD8+ lymphocytes. This may represent a druggable target to enhance immune-mediated tumor response, and there are currently ongoing trials evaluating this strategy [91,92]. Lastly, tumor-derived extracellular vesicles (EVs), which mediate cell-tocell interactions, have been shown to express PD-L1 and may contribute towards T cell suppression [93]. The impact of EVs has been shown to be relevant in HCC, as EV-derived molecules such as ubiquitin-like with PHD and RING finger domain (UHFR1) induce NK cell dysfunction in HCC patients [94].

\subsection{Adjuvant Immunotherapy in HCC}

There are multiple ongoing clinical trials evaluating the adjuvant use of immunotherapy in patients with intermediate stage HCC. As mentioned previously, there is preliminary evidence that tremelimumab combined with either TACE or RFA may represent a new therapeutic strategy for patients with earlier stage disease [34]. This strategy is being investigated in the IMbrave150, trial which is a randomized, open label, phase III study comparing atezolizumab and bevacizumab versus active surveillance in HCC patients after curative resection or RFA [95]. Additionally, the EMERALD-1 and EMERALD-2 trials are both randomized, double-blind, placebo-controlled phase III studies comparing durvalumab with or without bevacizumab to placebo in intermediate stage HCC patients receiving TACE or RFA $[96,97]$. If these studies show benefit for the use of adjuvant immunotherapy in HCC, this would further complicate treatment pathways, as the ideal treatment after progression on immunotherapy remains unclear.

\section{Conclusions}

The clinical trial data described above demonstrates limited efficacy for checkpoint inhibitor monotherapy for advanced HCC. However, combination therapies with checkpoint inhibitors and anti-VEGF treatments have shown promise for improving the poor survival data for advanced HCC. As we are just beginning to understand the applicability of immunotherapies to HCC, several new immunotherapy combinations are yet to be studied.

Author Contributions: Conceptualization, M.C. and J.G.; data curation, A.S. and R.J.B.; writingoriginal draft preparation, A.S. and R.J.B.; writing-review and editing, A.S., R.J.B., J.C.H., D.L., F.D., J.B.V., A.H., M.C., and J.G.; supervision, M.C. and J.G. All authors have read and agreed to the published version of the manuscript.

Funding: This research received no external funding. The sponsors had no role in the design, execution, interpretation, or writing of the study.

Conflicts of Interest: Dayyani is on the Speaker's Bureau for the companies Amgen, Deciphera, Eisai, Exelixis, Ipsen, Signatera, and Sirtex. He is on the Consulting/Advisory Board for the companies Signatera, QED, Ipsen, Genentech/Roche, Exelixis, Eisai, and AZD. He is part of research (to institution) for the companies AZD, BMS, Merck, Taiho, Ipsen, Exelixis, Roche, and Signatera. $\mathrm{Li}$ has received research grants from Brooklyn Immunotherapeutics and AstraZeneca and personal fees from Lexicon, Ipsen, Eisai, Exelixis, Advanced Accelerator Applications, Bayer, Genentech, Taiho, Coherus, Sun Pharma, and QED, all outside the submitted work. 


\section{References}

1. Ferlay, J.; Soerjomataram, I.; Dikshit, R.; Eser, S.; Mathers, C.; Rebelo, M.; Parkin, D.M.; Forman, D.; Bray, F. Cancer incidence and mortality worldwide: Sources, methods and major patterns in GLOBOCAN 2012. Int. J. Cancer 2015, 136, E359-E386. [CrossRef] [PubMed]

2. Llovet, J.M.; Ricci, S.; Mazzaferro, V.; Hilgard, P.; Gane, E.; Blanc, J.-F.; de Oliveira, A.C.; Santoro, A.; Raoul, J.-L.; Forner, A.; et al. Sorafenib in Advanced Hepatocellular Carcinoma. N. Engl. J. Med. 2008, 359, 378-390. [CrossRef] [PubMed]

3. Jenne, C.N.; Kubes, P. Immune surveillance by the liver. Nat. Immunol. 2013, 14, 996-1006. [CrossRef] [PubMed]

4. Doherty, D.G. Immunity, tolerance and autoimmunity in the liver: A comprehensive review. J. Autoimmun. 2016, 66, 60-75. [CrossRef]

5. Neuzillet, C.; de Mestier, L.; Rousseau, B.; Mir, O.; Hebbar, M.; Kocher, H.M.; Ruszniewski, P.; Tournigand, C. Unravelling the pharmacologic opportunities and future directions for targeted therapies in gastro-intestinal cancers part 2: Neuroendocrine tumours, hepatocellular carcinoma, and gastro-intestinal stromal tumours. Pharmacol. Ther. 2018, 181, 49-75. [CrossRef]

6. Fu, J.; Xu, D.; Liu, Z.; Shi, M.; Zhao, P.; Fu, B.; Zhang, Z.; Yang, H.; Zhang, H.; Zhou, C.; et al. Increased Regulatory T Cells Correlate with CD8 T-Cell Impairment and Poor Survival in Hepatocellular Carcinoma Patients. Gastroenterology 2007, 132, 2328-2339. [CrossRef]

7. Trehanpati, N.; Vyas, A.K. Immune Regulation by T Regulatory Cells in Hepatitis B Virus-Related Inflammation and Cancer. Scand. J. Immunol. 2017, 85, 175-181. [CrossRef]

8. Wang, B.J.; Bao, J.J.; Wang, J.Z.; Wang, Y.; Jiang, M.; Xing, M.Y.; Zhang, W.G.; Qi, J.Y.; Roggendorf, M.; Lu, M.J.; et al. Immunostaining of PD-1/PD-Ls in liver tissues of patients with hepatitis and hepatocellular carcinoma. World J. Gastroenterol. 2011, 17, 3322-3329. [CrossRef] [PubMed]

9. Ilkovitch, D.; Lopez, D.M. The liver is a site for tumor-induced myeloid-derived suppressor cell accumulation and immunosuppression. Cancer Res. 2009, 69, 5514-5521. [CrossRef]

10. Gao, Q.; Wang, X.Y.; Qiu, S.J.; Yamato, I.; Sho, M.; Nakajima, Y.; Zhou, J.; Li, B.Z.; Shi, Y.H.; Xiao, Y.S.; et al. Overexpression of PD-L1 significantly associates with tumor aggressiveness and postoperative recurrence in human hepatocellular carcinoma. Clin. Cancer Res. 2009, 15, 971-979. [CrossRef] [PubMed]

11. Shi, F.; Shi, M.; Zeng, Z.; Qi, R.Z.; Liu, Z.W.; Zhang, J.Y.; Yang, Y.P.; Tien, P.; Wang, F.S. PD-1 and PD-L1 upregulation promotes CD8+ T-cell apoptosis and postoperative recurrence in hepatocellular carcinoma patients. Int. J. Cancer 2011, 128, 887-896. [CrossRef]

12. Barber, D.L.; Wherry, E.J.; Masopust, D.; Zhu, B.; Allison, J.P.; Sharpe, A.H.; Freeman, G.J.; Ahmed, R. Restoring function in exhausted CD8 T cells during chronic viral infection. Nature 2006, 439, 682-687. [CrossRef] [PubMed]

13. Iwai, Y.; Terawaki, S.; Ikegawa, M.; Okazaki, T.; Honjo, T. PD-1 inhibits antiviral immunity at the effector phase in the liver. J. Exp. Med. 2003, 198, 39-50. [CrossRef] [PubMed]

14. Maier, H.; Isogawa, M.; Freeman, G.J.; Chisari, F.V. PD-1:PD-L1 Interactions Contribute to the Functional Suppression of Virus-Specific CD8 + T Lymphocytes in the Liver. J. Immunol. 2007, 178, 2714-2720. [CrossRef] [PubMed]

15. Zeng, Z.; Shi, F.; Zhou, L.; Zhang, M.N.; Chen, Y.; Chang, X.J.; Lu, Y.Y.; Bai, W.L.; Qu, J.H.; Wang, C.P.; et al. Upregulation of circulating PD-L1/PD-1 is associated with poor post-cryoablation prognosis in patients with HBV-related hepatocellular carcinoma. PLoS ONE 2011, 6. [CrossRef]

16. Shrestha, R.; Prithviraj, P.; Anaka, M.; Bridle, K.R.; Crawford, D.H.G.; Dhungel, B.; Steel, J.C.; Jayachandran, A. Monitoring immune checkpoint regulators as predictive biomarkers in hepatocellular carcinoma. Front. Oncol. 2018, 8. [CrossRef] [PubMed]

17. Langhans, B.; Nischalke, H.D.; Krämer, B.; Dold, L.; Lutz, P.; Mohr, R.; Vogt, A.; Toma, M.; Eis-Hübinger, A.M.; Nattermann, J.; et al. Role of regulatory $\mathrm{T}$ cells and checkpoint inhibition in hepatocellular carcinoma. Cancer Immunol. Immunother. 2019, 68, 2055-2066. [CrossRef]

18. Rotte, A. Combination of CTLA-4 and PD-1 blockers for treatment of cancer. J. Exp. Clin. Cancer Res. 2019, 38, 1-12. [CrossRef]

19. El-Khoueiry, A.B.; Sangro, B.; Yau, T.; Crocenzi, T.S.; Kudo, M.; Hsu, C.; Kim, T.Y.; Choo, S.P.; Trojan, J.; Welling, T.H.; et al. Nivolumab in patients with advanced hepatocellular carcinoma (CheckMate 040): An open-label, non-comparative, phase $1 / 2$ dose escalation and expansion trial. Lancet 2017, 389, 2492-2502. [CrossRef]

20. Yau, T.; Park, J.W.; Finn, R.S.; Cheng, A.-L.; Mathurin, P.; Edeline, J.; Kudo, M.; Han, K.-H.; Harding, J.J.; Merle, P.; et al. CheckMate 459: A randomized, multi-center phase III study of nivolumab (NIVO) vs sorafenib (SOR) as first-line (1L) treatment in patients (pts) with advanced hepatocellular carcinoma (aHCC). Ann. Oncol. 2019, 30, v874-v875. [CrossRef]

21. Zhu, A.X.; Finn, R.S.; Edeline, J.; Cattan, S.; Ogasawara, S.; Palmer, D.; Verslype, C.; Zagonel, V.; Fartoux, L.; Vogel, A.; et al. Pembrolizumab in patients with advanced hepatocellular carcinoma previously treated with sorafenib (KEYNOTE-224): A non-randomised, open-label phase 2 trial. Lancet Oncol. 2018, 19, 940-952. [CrossRef]

22. Finn, R.S.; Ryoo, B.Y.; Merle, P.; Kudo, M.; Bouattour, M.; Lim, H.Y.; Breder, V.; Edeline, J.; Chao, Y.; Ogasawara, S.; et al. Pembrolizumab As Second-Line Therapy in Patients with Advanced Hepatocellular Carcinoma in KEYNOTE-240: A Randomized, Double-Blind, Phase III Trial. J. Clin. Oncol. 2020, 38, 193-202. [CrossRef]

23. Finn, R.S.; Qin, S.; Ikeda, M.; Galle, P.R.; Ducreux, M.; Kim, T.-Y.; Kudo, M.; Breder, V.; Merle, P.; Kaseb, A.O.; et al. Atezolizumab plus Bevacizumab in Unresectable Hepatocellular Carcinoma. N. Engl. J. Med. 2020, 382, 1894-1905. [CrossRef]

24. Finn, R.S.; Qin, S.; Ikeda, M.; Galle, P.R.; Ducreux, M.; Kim, T.-Y.; Lim, H.Y.; Kudo, M.; Breder, V.V.; Merle, P.; et al. IMbrave150; Updated overall survival (OS) data from a global, randomized, open-label phase III study of atezolizumab (atezo) + bevacizumab 
(bev) versus sorafenib (sor) in patients (pts) with unresectable hepatocellular carcinoma (HCC). J. Clin. Oncol. 2021, $39,267$. [CrossRef]

25. Results from LENVIMA®(lenvatinib) Plus KEYTRUDA®(pembrolizumab) Trials in Unresectable Hepatocellular Carcinoma and Advanced Renal Cell Carcinoma to be Presented at 2020 ASCO Annual Meeting I News Release:2020 I Eisai Co., Ltd. Available online: https: / / www.eisai.com/news/2020/news202023.html (accessed on 17 February 2021).

26. A Trial of Lenvatinib Plus Pembrolizumab in Participants with Hepatocellular Carcinom. A-Full Text View-ClinicalTrials.gov. Available online: https:/ / clinicaltrials.gov/ct2/show / study/NCT03006926 (accessed on 17 February 2021).

27. Guo, L.; Zhang, H.; Chen, B. Nivolumab as Programmed Death-1 (PD-1) Inhibitor for Targeted Immunotherapy in Tumor. J. Cancer 2017, 8, 410-416. [CrossRef] [PubMed]

28. Onuma, A.E.; Zhang, H.; Huang, H.; Williams, T.M.; Noonan, A.; Tsung, A. Immune Checkpoint Inhibitors in Hepatocellular Cancer: Current Understanding on Mechanisms of Resistance and Biomarkers of Response to Treatment. Gene Expr. J. Liver Res. 2020, 20, 53-65. [CrossRef]

29. Comin-Anduix, B.; Escuin-Ordinas, H.; Ibarrondo, F.J. Tremelimumab: Research and clinical development. Onco Targets Ther. 2016, 9, 1767-1776.

30. Chambers, C.A.; Kuhns, M.S.; Egen, J.G.; Allison, J.P. CTLA-4-mediated inhibition in regulation of T cell responses: Mechanisms and manipulation in tumor immunotherapy. Annu. Rev. Immunol. 2001, 19, 565-594. [CrossRef] [PubMed]

31. Sangro, B.; Gomez-Martin, C.; De La Mata, M.; Iñarrairaegui, M.; Garralda, E.; Barrera, P.; Riezu-Boj, J.I.; Larrea, E.; Alfaro, C.; Sarobe, P.; et al. A clinical trial of CTLA-4 blockade with tremelimumab in patients with hepatocellular carcinoma and chronic hepatitis C. J. Hepatol. 2013, 59, 81-88. [CrossRef] [PubMed]

32. A Study of Durvalumab or Tremelimumab Monotherapy, or Durvalumab in Combination with Tremelimumab or Bevacizumab in Advanced Hepatocellular Carcinom. A-Full Text View-ClinicalTrials.gov. Available online: https://clinicaltrials.gov/ct2 / show / NCT02519348 (accessed on 2 February 2021).

33. Imfinzi Plus Tremelimumab Demonstrated Promising Clinical Activity and Tolerability in Patients with Advanced Liver Cancer. Available online: https:/ / www.astrazeneca.com/media-centre/press-releases/2020/imfinzi-plus-tremelimumab-demonstratedpromising-clinical-activity-and-tolerability-in-patients-with-advanced-liver-cancer.html (accessed on 17 February 2021).

34. Duffy, A.G.; Ulahannan, S.V.; Makorova-Rusher, O.; Rahma, O.; Wedemeyer, H.; Pratt, D.; Davis, J.L.; Hughes, M.S.; Heller, T.; ElGindi, M.; et al. Tremelimumab in combination with ablation in patients with advanced hepatocellular carcinoma. J. Hepatol. 2017, 66, 545-551. [CrossRef]

35. Syed, Y.Y. Durvalumab: First Global Approval. Drugs 2017, 77, 1369-1376. [CrossRef]

36. Wainberg, Z.A.; Segal, N.H.; Jaeger, D.; Lee, K.-H.; Marshall, J.; Antonia, S.J.; Butler, M.; Sanborn, R.E.; Nemunaitis, J.J.; Carlson, C.A.; et al. Safety and clinical activity of durvalumab monotherapy in patients with hepatocellular carcinoma (HCC). J. Clin. Oncol. 2017, 35, 4071. [CrossRef]

37. Hilmi, M.; Neuzillet, C.; Calderaro, J.; Lafdil, F.; Pawlotsky, J.M.; Rousseau, B. Angiogenesis and immune checkpoint inhibitors as therapies for hepatocellular carcinoma: Current knowledge and future research directions. J. Immunother. Cancer 2019, 7, 333. [CrossRef] [PubMed]

38. Yang, J.; Yan, J.; Liu, B. Targeting VEGF/VEGFR to modulate antitumor immunity. Front. Immunol. 2018, 9, 978. [CrossRef] [PubMed]

39. Morse, M.A.; Sun, W.; Kim, R.; He, A.R.; Abada, P.B.; Mynderse, M.; Finn, R.S. The role of angiogenesis in hepatocellular carcinoma. Clin. Cancer Res. 2019, 25, 912-920. [CrossRef]

40. Shigeta, K.; Datta, M.; Hato, T.; Kitahara, S.; Chen, I.X.; Matsui, A.; Kikuchi, H.; Mamessier, E.; Aoki, S.; Ramjiawan, R.R.; et al. Dual Programmed Death Receptor-1 and Vascular Endothelial Growth Factor Receptor-2 Blockade Promotes Vascular Normalization and Enhances Antitumor Immune Responses in Hepatocellular Carcinoma. Hepatology 2020, 71, 1247-1261. [CrossRef]

41. Hato, T.; Zhu, A.X.; Duda, D.G. Rationally combining anti-VEGF therapy with checkpoint inhibitors in hepatocellular carcinoma. Immunotherapy 2016, 8, 299-313. [CrossRef]

42. Lee, H.T.; Lee, J.Y.; Lim, H.; Lee, S.H.; Moon, Y.J.; Pyo, H.J.; Ryu, S.E.; Shin, W.; Heo, Y.S. Molecular mechanism of PD-1/PD-L1 blockade via anti-PD-L1 antibodies atezolizumab and durvalumab. Sci. Rep. 2017, 7. [CrossRef]

43. Frampton, J.E. Atezolizumab: A Review in Extensive-Stage SCLC. Drugs 2020, 80, 1587-1594. [CrossRef]

44. Elamin, Y.Y.; Rafee, S.; Toomey, S.; Hennessy, B.T. Immune Effects of Bevacizumab: Killing Two Birds with One Stone. Cancer Microenviron. 2015, 8, 15-21. [CrossRef]

45. Garcia, J.; Hurwitz, H.I.; Sandler, A.B.; Miles, D.; Coleman, R.L.; Deurloo, R.; Chinot, O.L. Bevacizumab (Avastin ${ }^{\circledR}$ ) in cancer treatment: A review of 15 years of clinical experience and future outlook. Cancer Treat. Rev. 2020, 86. [CrossRef]

46. Lee, M.S.; Ryoo, B.Y.; Hsu, C.H.; Numata, K.; Stein, S.; Verret, W.; Hack, S.P.; Spahn, J.; Liu, B.; Abdullah, H.; et al. Atezolizumab with or without bevacizumab in unresectable hepatocellular carcinoma (GO30140): An open-label, multicentre, phase 1b study. Lancet Oncol. 2020, 21, 808-820. [CrossRef]

47. Randomised Efficacy and Safety Results for Atezolizumab (Atezo) + Bevacizumab (Bev) in Patients (pts) with Previously Untreated, Unresectable Hepat... I OncologyPRO. Available online: https:/ / oncologypro.esmo.org/meeting-resources/esmo2019-congress / Randomised-Efficacy-and-Safety-Results-For-Atezolizumab-Atezo-Bevacizumab-Bev-in-Patients-pts-WithPreviously-Untreated-Unresectable-Hepatocellular-Carcinoma-HCC (accessed on 7 February 2021). 
48. Kudo, M.; Finn, R.S.; Qin, S.; Han, K.H.; Ikeda, K.; Piscaglia, F.; Baron, A.; Park, J.W.; Han, G.; Jassem, J.; et al. Lenvatinib versus sorafenib in first-line treatment of patients with unresectable hepatocellular carcinoma: A randomised phase 3 non-inferiority trial. Lancet 2018, 391, 1163-1173. [CrossRef]

49. Melero, I.; Berman, D.M.; Aznar, M.A.; Korman, A.J.; Gracia, J.L.P.; Haanen, J. Evolving synergistic combinations of targeted immunotherapies to combat cancer. Nat. Rev. Cancer 2015, 15, 457-472. [CrossRef] [PubMed]

50. Kelley, R.K.; Sangro, B.; Harris, W.P.; Ikeda, M.; Okusaka, T.; Kang, Y.-K.; Qin, S.; Tai, W.M.D.; Lim, H.Y.; Yau, T.; et al. Efficacy, tolerability, and biologic activity of a novel regimen of tremelimumab (T) in combination with durvalumab (D) for patients (pts) with advanced hepatocellular carcinoma (aHCC). J. Clin. Oncol. 2020, 38, 4508. [CrossRef]

51. Yau, T.; Kang, Y.K.; Kim, T.Y.; El-Khoueiry, A.B.; Santoro, A.; Sangro, B.; Melero, I.; Kudo, M.; Hou, M.M.; Matilla, A.; et al Efficacy and Safety of Nivolumab plus Ipilimumab in Patients with Advanced Hepatocellular Carcinoma Previously Treated with Sorafenib: The CheckMate 040 Randomized Clinical Trial. JAMA Oncol. 2020, 6. [CrossRef] [PubMed]

52. Sangro, B.; Melero, I.; Wadhawan, S.; Finn, R.S.; Abou-Alfa, G.K.; Cheng, A.L.; Yau, T.; Furuse, J.; Park, J.W.; Boyd, Z.; et al. Association of inflammatory biomarkers with clinical outcomes in nivolumab-treated patients with advanced hepatocellular carcinoma. J. Hepatol. 2020, 73, 1460-1469. [CrossRef]

53. A Study of Nivolumab in Combination with Ipilimumab in Participants with Advanced Hepatocellular Carcinom. A-Full Text View_ClinicalTrials.gov. Available online: https:/ / clinicaltrials.gov/ct2/show/NCT04039607 (accessed on 2 February 2021).

54. Suyama, K.; Iwase, H. Lenvatinib: A Promising Molecular Targeted Agent for Multiple Cancers. Cancer Control 2018, 25. [CrossRef]

55. Llovet, J.M.; Kudo, M.; Cheng, A.-L.; Finn, R.S.; Galle, P.R.; Kaneko, S.; Meyer, T.; Qin, S.; Dutcus, C.E.; Chen, E.; et al. Lenvatinib (len) plus pembrolizumab (pembro) for the first-line treatment of patients (pts) with advanced hepatocellular carcinoma (HCC): Phase 3 LEAP-002 study. J. Clin. Oncol. 2019, 37, TPS4152. [CrossRef]

56. Safety and Efficacy of Lenvatinib (E7080/MK-7902) in Combination with Pembrolizumab (MK-3475) Versus Lenvatinib as Firstline Therapy in Participants with Advanced Hepatocellular Carcinoma (MK-7902-002/E7080-G000-311/LEAP-002)—Full Text View-ClinicalTrials.gov. Available online: https:/ / clinicaltrials.gov/ct2/show / NCT03713593 (accessed on 2 February 2021).

57. Teng, R.; Zhao, J.; Zhao, Y.; Gao, J.; Li, H.; Zhou, S.; Wang, Y.; Sun, Q.; Lin, Z.; Yang, W.; et al. Chimeric Antigen Receptormodified T Cells Repressed Solid Tumors and Their Relapse in an Established Patient-derived Colon Carcinoma Xenograft Model. J. Immunother. 2019, 42, 33-42. [CrossRef]

58. Beatty, G.L.; O'Hara, M. Chimeric antigen receptor-modified T cells for the treatment of solid tumors: Defining the challenges and next steps. Pharmacol. Ther. 2016, 166, 30-39. [CrossRef]

59. Song, E.Z.; Milone, M.C. Pharmacology of Chimeric Antigen Receptor-Modified T Cells. Annu. Rev. Pharmacol. Toxicol. 2021, 61, 805-829. [CrossRef]

60. Chen, Y.; Chang Yong, E.; Gong, Z.W.; Liu, S.; Wang, Z.X.; Yang, Y.S.; Zhang, X.W. Chimeric antigen receptor-engineered T-cell therapy for liver cancer. Hepatobiliary Pancreat. Dis. Int. 2018, 17, 301-309. [CrossRef] [PubMed]

61. Haruyama, Y.; Kataoka, H. Glypican-3 is a prognostic factor and an immunotherapeutic target in hepatocellular carcinoma. World J. Gastroenterol. 2016, 22, 275-283. [CrossRef] [PubMed]

62. Bell, M.M.; Gutsche, N.T.; King, A.P.; Baidoo, K.E.; Kelada, O.J.; Choyke, P.L.; Escorcia, F.E. Glypican-3-Targeted Alpha Particle Therapy for Hepatocellular Carcinoma. Molecules 2020, 26, 4. [CrossRef] [PubMed]

63. Montaño-Samaniego, M.; Bravo-Estupiñan, D.M.; Méndez-Guerrero, O.; Alarcón-Hernández, E.; Ibáñez-Hernández, M. Strategies for Targeting Gene Therapy in Cancer Cells with Tumor-Specific Promoters. Front. Oncol. 2020, 10, 2671. [CrossRef] [PubMed]

64. Gillespie, J.R.; Uversky, V.N. Structure and function of $\alpha$-fetoprotein: A biophysical overview. Biochim. Biophys. Acta Protein Struct. Mol. Enzymol. 2000, 1480, 41-56. [CrossRef]

65. Liu, H.; Xu, Y.; Xiang, J.; Long, L.; Green, S.; Yang, Z.; Zimdahl, B.; Lu, J.; Cheng, N.; Horan, L.H.; et al. Targeting alpha-fetoprotein (AFP)-MHC complex with CART-cell therapy for liver cancer. Clin. Cancer Res. 2017, 23, 478-488. [CrossRef]

66. Clinical Study of ET1402L1-CAR T Cells in AFP Expressing Hepatocellular Carcinoma-Full Text View-ClinicalTrials.gov. Available online: https: / clinicaltrials.gov/ct2/show / NCT03349255 (accessed on 21 February 2021).

67. Rodriguez-Garcia, A.; Palazon, A.; Noguera-Ortega, E.; Powell, D.J.; Guedan, S. CAR-T Cells Hit the Tumor Microenvironment: Strategies to Overcome Tumor Escape. Front. Immunol. 2020, 11. [CrossRef]

68. Morgan, M.A.; Schambach, A. Engineering CAR-T Cells for Improved Function against Solid Tumors. Front. Immunol. 2018, 9, 2493. [CrossRef]

69. A Study of ERY974 in Patient with Advanced Solid Tumors-Full Text View-ClinicalTrials.gov. Available online: https: / / clinicaltrials.gov/ct2/show / NCT02748837 (accessed on 17 February 2021).

70. Cui, T.M.; Liu, Y.; Wang, J.B.; Liu, L.X. Adverse effects of immune-checkpoint inhibitors in hepatocellular carcinoma. Onco Targets Ther. 2020, 13, 11725-11740. [CrossRef] [PubMed]

71. Sangro, B.; Chan, S.L.; Meyer, T.; Reig, M.; El-Khoueiry, A.; Galle, P.R. Diagnosis and management of toxicities of immune checkpoint inhibitors in hepatocellular carcinoma. J. Hepatol. 2020, 72, 320-341. [CrossRef]

72. De Velasco, G.; Je, Y.; Bossé, D.; Awad, M.M.; Ott, P.A.; Moreira, R.B.; Schutz, F.; Bellmunt, J.; Sonpavde, G.P.; Hodi, F.S.; et al. Comprehensive meta-analysis of key immune-related adverse events from CTLA-4 and PD-1/PD-L1 inhibitors in cancer patients. Cancer Immunol. Res. 2017, 5, 312-318. [CrossRef] [PubMed] 
73. Thompson, J.A.; Schneider, B.J.; Brahmer, J.; Andrews, S.; Armand, P.; Bhatia, S.; Budde, L.E.; Costa, L.; Davies, M.; Dunnington, D.; et al. Management of immunotherapy-related toxicities, version 1.2020 featured updates to the NCCN guidelines. JNCCN J. Natl. Compr. Cancer Netw. 2020, 18, 231-241. [CrossRef]

74. Haanen, J.B.A.G.; Carbonnel, F.; Robert, C.; Kerr, K.M.; Peters, S.; Larkin, J.; Jordan, K. Management of toxicities from immunotherapy: ESMO Clinical Practice Guidelines for diagnosis, treatment and follow-up. Ann. Oncol. 2017, 28, iv119-iv142. [CrossRef] [PubMed]

75. Maus, M.V.; Alexander, S.; Bishop, M.R.; Brudno, J.N.; Callahan, C.; Davila, M.L.; Diamonte, C.; Dietrich, J.; Fitzgerald, J.C.; Frigault, M.J.; et al. Society for Immunotherapy of Cancer (SITC) clinical practice guideline on immune effector cell-related adverse events. J. Immunother. Cancer 2020, 8, 1511. [CrossRef] [PubMed]

76. A Study to Evaluate SHR-1210 in Combination with Apatinib as First-Line Therapy in Patients with Advanced HCC-Full Text View-ClinicalTrials.gov. Available online: https:/ / clinicaltrials.gov/ct2/show / NCT03764293 (accessed on 2 February 2021).

77. Study of Cabozantinib in Combination with Atezolizumab Versus Sorafenib in Subjects with Advanced HCC Who Have Not Received Previous Systemic Anticancer Therapy_Full Text View-ClinicalTrials.gov. Available online: https://clinicaltrials.gov/ ct2/show/NCT03755791 (accessed on 2 February 2021).

78. Study of Durvalumab and Tremelimumab as First-line Treatment in Patients with Advanced Hepatocellular Carcinom. A-Full Text View-ClinicalTrials.gov. Available online: https:/ / clinicaltrials.gov/ct2/show /NCT03298451 (accessed on 2 February 2021).

79. A Study to Evaluate the Efficacy and Safety of Sintilimab in Combination with IBI305 (Anti-VEGF Monoclonal Antibody) Compared to Sorafenib as the First-Line Treatment for Advanced Hepatocellular Carcinoma-Full Text View-ClinicalTrials.gov. Available online: https: / clinicaltrials.gov/ct2/show /NCT03794440 (accessed on 2 February 2021).

80. Phase 3 Study of Tislelizumab Versus Sorafenib in Participants with Unresectable HCC—Full Text View-ClinicalTrials.gov. Available online: https:/ / clinicaltrials.gov / ct2/show /NCT03412773 (accessed on 2 February 2021).

81. Brunnström, H.; Johansson, A.; Westbom-Fremer, S.; Backman, M.; Djureinovic, D.; Patthey, A.; Isaksson-Mettävainio, M.; Gulyas, M.; Micke, P. PD-L1 immunohistochemistry in clinical diagnostics of lung cancer: Inter-pathologist variability is higher than assay variability. Mod. Pathol. 2017, 30, 1411-1421. [CrossRef] [PubMed]

82. Kaseb, A.O.; Vence, L.; Blando, J.; Yadav, S.S.; Ikoma, N.; Pestana, R.C.; Vauthey, J.N.; Allison, J.P.; Sharma, P. Immunologic correlates of pathologic complete response to preoperative immunotherapy in hepatocellular carcinoma. Cancer Immunol. Res. 2019, 7, 1390-1395. [CrossRef]

83. Xie, F.; Bai, Y.; Yang, X.; Long, J.; Mao, J.; Lin, J.; Wang, D.; Song, Y.; Xun, Z.; Huang, H.; et al. Comprehensive analysis of tumour mutation burden and the immune microenvironment in hepatocellular carcinoma. Int. Immunopharmacol. 2020, 89. [CrossRef]

84. Büttner, R.; Longshore, J.W.; López-Ríos, F.; Merkelbach-Bruse, S.; Normanno, N.; Rouleau, E.; Penault-Llorca, F. Implementing TMB measurement in clinical practice: Considerations on assay requirements. ESMO Open 2019, 4, e000442. [CrossRef]

85. Ang, C.; Miura, J.T.; Clark Gamblin, T.; He, R.; Xiu, J.; Millis, S.Z.; Gatalica, Z.; Reddy, S.K.; Yee, N.S.; Abou-Alfa, G.K. Comprehensive multiplatform biomarker analysis of 350 hepatocellular carcinomas identifies potential novel therapeutic options. J. Surg. Oncol. 2016, 113, 55-61. [CrossRef] [PubMed]

86. Thorsson, V.; Gibbs, D.L.; Brown, S.D.; Wolf, D.; Bortone, D.S.; Ou Yang, T.H.; Porta-Pardo, E.; Gao, G.F.; Plaisier, C.L.; Eddy, J.A.; et al. The Immune Landscape of Cancer. Immunity 2018, 48, 812-830.e14. [CrossRef] [PubMed]

87. Motzer, R.J.; Robbins, P.B.; Powles, T.; Albiges, L.; Haanen, J.B.; Larkin, J.; Mu, X.J.; Ching, K.A.; Uemura, M.; Pal, S.K.; et al. Avelumab plus axitinib versus sunitinib in advanced renal cell carcinoma: Biomarker analysis of the phase 3 JAVELIN Renal 101 trial. Nat. Med. 2020, 26, 1733-1741. [CrossRef] [PubMed]

88. Taylor, M.H.; Lee, C.H.; Makker, V.; Rasco, D.; Dutcus, C.E.; Wu, J.; Stepan, D.E.; Shumaker, R.C.; Motzer, R.J. Phase Ib/II trial of lenvatinib plus pembrolizumab in patients with advanced renal cell carcinoma, endometrial cancer, and other selected advanced solid tumors. J. Clin. Oncol. Am. Soc. Clin. Oncol. 2020, 38, 1154-1163. [CrossRef]

89. Martin, C.J.; Datta, A.; Littlefield, C.; Kalra, A.; Chapron, C.; Wawersik, S.; Dagbay, K.B.; Brueckner, C.T.; Nikiforov, A.; Danehy, F.T; et al. Selective inhibition of TGF $\beta 1$ activation overcomes primary resistance to checkpoint blockade therapy by altering tumor immune landscape. Sci. Transl. Med. 2020, 12. [CrossRef] [PubMed]

90. Li, F.J.; Zhang, Y.; Jin, G.X.; Yao, L.; Wu, D.Q. Expression of LAG-3 is coincident with the impaired effector function of HBV-specific CD8+ T cell in HCC patients. Immunol. Lett. 2013, 150, 116-122. [CrossRef]

91. Anderson, A.C. Tim-3: An emerging target in the cancer immunotherapy landscape. Cancer Immunol. Res. 2014, 2, 393-398. [CrossRef] [PubMed]

92. TSR-022 (Anti-TIM-3 Antibody) and TSR-042 (Anti-PD-1 Antibody) in Patients with Liver Cancer-Full Text ViewClinicalTrials.gov. Available online: https:/ / clinicaltrials.gov/ct2/show / NCT03680508 (accessed on 3 February 2021).

93. Zhang, D.X.; Vu, L.T.; Ismail, N.N.; Le, M.T.N.; Grimson, A. Landscape of extracellular vesicles in the tumour microenvironment: Interactions with stromal cells and with non-cell components, and impacts on metabolic reprogramming, horizontal transfer of neoplastic traits, and the emergence of therapeutic resistance. Semin. Cancer Biol. 2021. [CrossRef]

94. Zhang, P.F.; Zhang, P.F.; Zhang, P.F.; Gao, C.; Gao, C.; Huang, X.Y.; Huang, X.Y.; Lu, J.C.; Lu, J.C.; Guo, X.J.; et al. Cancer cellderived exosomal circUHRF1 induces natural killer cell exhaustion and may cause resistance to anti-PD1 therapy in hepatocellular carcinoma. Mol. Cancer 2020, 19, 110. [CrossRef] 
95. Hack, S.P.; Spahn, J.; Chen, M.; Cheng, A.L.; Kaseb, A.; Kudo, M.; Lee, H.C.; Yopp, A.; Chow, P.; Qin, S. IMbrave 050: A Phase III trial of atezolizumab plus bevacizumab in high-risk hepatocellular carcinoma after curative resection or ablation. Future Oncol. 2020, 16, 975-989. [CrossRef]

96. Sangro, B.; Kudo, M.; Qin, S.; Ren, Z.; Chan, S.; Joseph, E.; Arai, Y.; Mann, H.; Morgan, S.; Cohen, G.; et al. P-347 A phase 3 , randomized, double-blind, placebo-controlled study of transarterial chemoembolization combined with durvalumab or durvalumab plus bevacizumab therapy in patients with locoregional hepatocellular carcinoma: EMERALD-1. Ann. Oncol. 2020, 31, S202-S203. [CrossRef]

97. Knox, J.; Cheng, A.; Cleary, S.; Galle, P.; Kokudo, N.; Lencioni, R.; Park, J.; Zhou, J.; Mann, H.; Morgan, S.; et al. A phase 3 study of durvalumab with or without bevacizumab as adjuvant therapy in patients with hepatocellular carcinoma at high risk of recurrence after curative hepatic resection or ablation: EMERALD-2. Ann. Oncol. 2019, 30, iv59-iv60. [CrossRef] 